\author{
Witold Sobczak (D) \\ Uniwersytet Łódzki \\ witold.sobczak@uni.lodz.pl
}

\title{
Sobre la expresión de posterioridad en el español peninsular y en su variedad mexicana en los años 1929-2015
}

\begin{abstract}
Resumen:
El presente artículo gira en torno a los cambios que se produjeron entre las formas de posterioridad en el español peninsular y en su variedad mexicana en los años 1929-2015. Basándonos en nuestro propio corpus que comprende veinte novelas (diez españolas y diez mexicanas), no solo llamamos la atención sobre la repartición de cantará, va a cantar y canta, sino que también analizamos con detenimiento el uso de cantaría, iba a cantar y cantaba. Además, nuestro análisis abarca las llamadas formas acompañantes: vaya a cantar, fuera a cantar, fuese a cantar, irá a cantar, iría a cantar, va a haber cantado e iba a haber cantado.
\end{abstract} Palabras clave: futuro, posterioridad, modalidad, cambio lingüístico, sistema temporal castellano

\begin{abstract}
:
On the Expression of Posteriority in Peninsular and Mexican Spanish between 1929 and 2015

This article aims to comment on the changes which took place among forms expressing posteriority in Peninsular and Mexican Spanish between 1929-2015. The study is based on a prepared corpus which is comprised of twenty novels (ten Spanish and ten Mexican). Emphasis is not only put on the distribution of cantará, va a cantar y canta, but also on the in-depth analysis of the usage of cantaria, iba a cantar, y cantaba. Furthermore, the analysis includes the so-called
\end{abstract}


accompanying forms, such as vaya a cantar, fuera a cantar, fuese a cantar, irá a cantar, iría a cantar, va a haber cantado e iba a haber cantado.

Keywords: future, posteriority, modality, linguistic change, Spanish tense system

\section{Introducción}

Como se señala en repetidas ocasiones, el reemplazo del futuro sintético por el analítico constituye un tema clásico en los estudios sincrónicos y diacrónicos de la lingüística románica, puesto que dicho proceso no se documenta exclusivamente en castellano, sino también en otras lenguas pertenecientes al mismo grupo, p. ej. en francés, gallego y portugués (Schwegler, 1990). Sin lugar a dudas, estamos ante uno de los cambios lingüísticos más apasionantes que se repite a partir de la época del latín clásico (Fleischman, 1982: 103-110; Hopper y Traugott, 2003: 9-10) y sigue suscitando el interés por parte de muchos lingüistas. Aunque se ha publicado un gran número de trabajos donde se profundizan distintos aspectos de la sustitución de una forma por la otra (véanse, por ejemplo: Bauhr, 1989; Aaron, 2007; Bravo, 2008; Laca, 2016), es indudable que el desarrollo funcional de la perífrasis ir a + infinitivo no deja de sorprendernos y todavía quedan por resolver varias cuestiones.

En las páginas que siguen, vamos a centrar la atención en el uso de las formas de posterioridad en España y México en el período que comprende los años entre 1929 y 2015. Se trata, por tanto, de un estudio comparativo de índole diacrónico-sincrónico en el que hemos de tener muy en cuenta las diferencias registradas entre el español peninsular y una de sus variedades americanas. A fin de aportar algunas nuevas observaciones a las investigaciones dedicadas a este problema, no vamos a limitar nuestro análisis a las formas cantará, va a cantar y canta, utilizada con referencia a lo venidero, sino que también vamos a tratar con detenimiento el empleo de cantaría, iba a cantar, cantaba, que, como es bien sabido, denotan, entre otros, posterioridad con respecto a un momento anterior al origen. Además de ello, vamos a comentar el uso de las formas vaya a cantar, fuera a cantar, fuese 
a cantar, irá a cantar, iría a cantar, va a haber cantado e iba a haber cantado cuya presencia en la lengua sugiere que el desarrollo de la perífrasis no se ha llevado a cabo todavía.

El propósito principal de nuestra contribución es observar y explicar cómo cambió la repartición de las formas mencionadas supra desde 1929 hasta 2015 y hasta qué punto la sustitución del futuro sintético por el analítico, fenómeno típico de la lengua hablada, repercute en los textos de narrativa. Una vez contestadas estas preguntas, intentaremos determinar si cantará y cantaría empleadas con valor temporal caen paulatinamente en desuso en lo escrito o mantienen una posición estable.

\section{Corpus}

Antes de elegir las obras literarias para el corpus, establecimos una serie de criterios que vamos a comentar concisa y brevemente. Así pues, los textos seleccionados abarcan un período de más de ochenta años, que consideramos bastante extenso para poder observar algunos cambios sucedidos en la lengua. Sin embargo, a diferencia de numerosos estudios de índole diacrónica, la época elegida no corresponde a ninguna etapa de evolución literaria, sino que, antes bien, se ve determinada por el fenómeno lingüístico del florecimiento de la perífrasis ir $a+$ infinitivo. Este fenómeno que era creciente desde el siglo XIX, registra una intensificación a mediados del siglo XX.

Por otra parte, la literatura seleccionada varía diatópicamente entre sí, ya que en los trabajos dedicados a las formas de posterioridad los autores apuntan que el reemplazo de los tiempos sintéticos, es decir, el futuro (cantará) y el pospretérito (cantaría) por la construcción perifrástica se produce más rápidamente y es más visible en el español de América que en el de la Península. Por ello, a fin de comprobar cómo difiere el ritmo de dicha sustitución en estas dos variedades, hemos decidido comparar las obras mexicanas con las españolas. Creemos que México, al ser el país más grande de habla hispana, nos puede servir como un buen punto de referencia para estudiar el cambio lingüístico que nos interesa. 


\section{Novelas españolas:}

1. Unamuno, M. de (1930), San Manuel Bueno, mártir y tres historias más

2. Sendero, J. M. (1942), Epitalamio del prieto Trinidad

3. Cela, C. J. (1950), La colmena

4. Salvador, T. (1960), El atentado

5. Marsé, J. (1970), La oscura historia de la prima Montse

6. García Hortelano, J. (1982), Gramática parda

7. Marías, J. (1992), Corazón tan blanco

8. Pérez-Reverte, A. (2000), El oro del rey

9. Barba, A. (2008), Las manos pequeñas

10. Moro, J. (2015), A flor de piel

\section{Novelas mexicanas:}

1. Guzmán, M. L. (1929), La sombra del caudillo

2. Romero, J. R. (1938), La vida inútil de Pito Pérez

3. Yáñez, A. (1947), Al filo del agua

4. Rulfo, J. (1955), Pedro Páramo

5. Fuentes, C. (1967), Cambio de piel

6. Ibargüengoitia, J. (1979), Dos crimenes

7. Serena, E. (1987), Señorita México

8. Volpi, J. (1995), La paz de los sepulcros

9. Cuauhtémoc Sánchez, C. (2004), Los ojos de mi princesa 10. Poniatowska, E. (2015), Dos veces única

Conviene indicar que el lapso que media entre la fecha de publicación de dos obras consecutivas es de entre siete y doce años. Aunque es imposible que la extensión de cada una de las novelas estudiadas sea la misma, hemos calculado el volumen total del material recopilado, de modo que abarque unas 2500 páginas para cada una de las variedades lingüísticas.

El cómputo total de las formas que constituyen el corpus es de 10139 y engloba, por un lado, el futuro (cantará), el pospretérito (cantaría), el presente pro futuro (canta) y el copretérito (cantaba) utilizado con referencia a lo venidero, así como la perífrasis ir $a+$ 
Sobre la expresión de posterioridad en el español peninsular...

infinitivo con verbo en presente ( $v a$ a cantar) y en copretérito (iba a cantar). Dado que en nuestra investigación pretendemos hacer una serie de observaciones sobre todo en torno a la lengua contemporánea, el corpus comprende también las llamadas "formas acompañantes”, a saber, las que derivan de ir $a+$ infinitivo, aunque se emplean en pocas ocasiones. Nos referimos en concreto a: vaya a cantar, fuera a cantar, fuese a cantar, irá a cantar, iría a cantar, va a haber cantado, iba a haber cantado.

Tabla 1. Repartición general de formas por años en el español peninsular

\begin{tabular}{|l|c|c|c|c|c|c|c|c|c|c|c|}
\hline Forma & $\mathbf{1 9 3 0}$ & $\mathbf{1 9 4 2}$ & $\mathbf{1 9 5 0}$ & $\mathbf{1 9 6 0}$ & $\mathbf{1 9 7 0}$ & $\mathbf{1 9 8 2}$ & $\mathbf{1 9 9 2}$ & $\mathbf{2 0 0 0}$ & $\mathbf{2 0 0 8}$ & $\mathbf{2 0 1 5}$ & $\begin{array}{c}\text { To- } \\
\text { tal }\end{array}$ \\
\hline canta & 11 & 14 & 65 & 21 & 21 & 20 & 16 & 18 & 3 & 17 & $\mathbf{2 0 6}$ \\
\hline cantará & 117 & 172 & 230 & 218 & 253 & 333 & 244 & 127 & 31 & 302 & $\mathbf{2 0 2 7}$ \\
\hline $\begin{array}{l}\text { va a can- } \\
\text { tar }\end{array}$ & 20 & 70 & 75 & 42 & 20 & 43 & 41 & 3 & 8 & 101 & $\mathbf{4 2 3}$ \\
\hline cantaba & 1 & 5 & 4 & 0 & 12 & 0 & 10 & 3 & 0 & 3 & $\mathbf{3 8}$ \\
\hline cantaría & 60 & 216 & 122 & 135 & 224 & 239 & 278 & 72 & 104 & 365 & $\mathbf{1 8 1 5}$ \\
\hline $\begin{array}{l}\text { iba } \\
\text { a cantar }\end{array}$ & 7 & 45 & 12 & 4 & 12 & 11 & 41 & 25 & 14 & 38 & $\mathbf{2 0 9}$ \\
\hline $\begin{array}{l}\text { vaya } \\
\text { a cantar }\end{array}$ & 0 & 1 & 4 & 1 & 1 & 3 & 2 & 1 & 0 & 0 & $\mathbf{1 3}$ \\
\hline $\begin{array}{l}\text { fuera } \\
\text { a cantar }\end{array}$ & 0 & 1 & 1 & 1 & 1 & 2 & 8 & 1 & 2 & 4 & $\mathbf{2 1}$ \\
\hline $\begin{array}{l}\text { fuese } \\
\text { a cantar }\end{array}$ & 0 & 0 & 0 & 0 & 1 & 0 & 0 & 1 & 0 & 6 & $\mathbf{8}$ \\
\hline $\begin{array}{l}\text { irá } \\
\text { a cantar }\end{array}$ & 0 & 0 & 0 & 0 & 0 & 0 & 0 & 0 & 0 & 0 & $\mathbf{0}$ \\
\hline $\begin{array}{l}\text { iría } \\
\text { a cantar }\end{array}$ & 0 & 0 & 0 & 0 & 0 & 0 & 0 & 0 & 0 & 0 & $\mathbf{0}$ \\
\hline $\begin{array}{l}\text { va } \\
\text { a haber } \\
\text { cantado }\end{array}$ & 0 & 0 & 0 & 0 & 0 & 0 & 0 & 0 & 0 & 0 & $\mathbf{0}$ \\
\hline $\begin{array}{l}\text { iba } \\
\text { a haber } \\
\text { cantado }\end{array}$ & 0 & 0 & 0 & 0 & 0 & 0 & 0 & 0 & 0 & 0 & $\mathbf{0}$ \\
\hline
\end{tabular}


Tabla 2. Repartición general de formas por años en el español de México

\begin{tabular}{|l|c|c|c|c|c|c|c|c|c|c|c|}
\hline Forma & $\mathbf{1 9 2 9}$ & $\mathbf{1 9 3 8}$ & $\mathbf{1 9 4 7}$ & $\mathbf{1 9 5 5}$ & $\mathbf{1 9 6 7}$ & $\mathbf{1 9 7 9}$ & $\mathbf{1 9 8 7}$ & $\mathbf{1 9 9 5}$ & $\mathbf{2 0 0 4}$ & $\mathbf{2 0 1 5}$ & Total \\
\hline canta & 26 & 8 & 30 & 5 & 20 & 42 & 15 & 2 & 34 & 65 & $\mathbf{2 4 7}$ \\
\hline cantará & 137 & 62 & 575 & 205 & 505 & 74 & 40 & 49 & 377 & 229 & $\mathbf{2 2 5 3}$ \\
\hline $\begin{array}{l}\text { va a can- } \\
\text { tar }\end{array}$ & 39 & 20 & 119 & 50 & 135 & 79 & 72 & 15 & 111 & 271 & $\mathbf{9 1 1}$ \\
\hline cantaba & 1 & 0 & 0 & 1 & 3 & 0 & 6 & 0 & 1 & 0 & $\mathbf{1 2}$ \\
\hline cantaria & 105 & 24 & 320 & 73 & 330 & 66 & 138 & 211 & 219 & 140 & $\mathbf{1 6 2 6}$ \\
\hline $\begin{array}{l}\text { iba } \\
\text { a cantar }\end{array}$ & 22 & 3 & 23 & 11 & 56 & 51 & 36 & 15 & 25 & 5 & $\mathbf{2 4 7}$ \\
\hline $\begin{array}{l}\text { vaya } \\
\text { a cantar }\end{array}$ & 1 & 2 & 11 & 2 & 5 & 1 & 8 & 1 & 2 & 13 & $\mathbf{4 6}$ \\
\hline $\begin{array}{l}\text { fuera } \\
\text { a cantar }\end{array}$ & 1 & 0 & 5 & 2 & 2 & 0 & 5 & 0 & 1 & 2 & $\mathbf{1 8}$ \\
\hline $\begin{array}{l}\text { fuese } \\
\text { a cantar }\end{array}$ & 1 & 0 & 2 & 0 & 0 & 0 & 0 & 4 & 0 & 0 & $\mathbf{7}$ \\
\hline $\begin{array}{l}\text { irá } \\
\text { a cantar }\end{array}$ & 0 & 0 & 10 & 0 & 0 & 0 & 0 & 0 & 0 & 0 & $\mathbf{1 0}$ \\
\hline $\begin{array}{l}\text { iría } \\
\text { a cantar }\end{array}$ & 0 & 0 & 2 & 0 & 0 & 0 & 0 & 0 & 0 & 0 & $\mathbf{2}$ \\
\hline $\begin{array}{l}\text { va } \\
\text { a haber } \\
\text { cantado }\end{array}$ & 0 & 0 & 0 & 0 & 0 & 0 & 0 & 0 & 0 & 0 & $\mathbf{0}$ \\
\hline $\begin{array}{l}\text { iba } \\
\text { a haber } \\
\text { cantado }\end{array}$ & 0 & 0 & 0 & 0 & 0 & 0 & 0 & 0 & 0 & 0 & $\mathbf{0}$ \\
\hline
\end{tabular}

Como se aprecia en las tablas 1 y 2, el número de ejemplos recopilados parece bastante representativo y, en nuestra opinión, permite realizar un estudio pormenorizado de las formas en cuestión con el objetivo de extraer algunas conclusiones acerca de los cambios sucedidos entre los años 1929 y 2015.

No cabe la menor duda de que los datos globales indican que en el español de México es mucho más común el empleo de la perífrasis con verbo en presente que en el de la Península (911 vs. 423 casos). En cambio, la diferencia entre la repartición de cantará, cantaría e iba 
a cantar ya no parece tan sorprendente y sería difícil señalar un claro predominio de alguna de estas formas en una de las variedades nos interesan. Recordemos que el uso de las formas acompañantes se documenta con mayor frecuencia en el español de América que en el europeo. En el caso de nuestro corpus llama la atención, ante todo, el contraste que se da en el empleo de vaya $a+$ infinitivo (46 vs. 13 formas).

\section{Español peninsular}

Gráfico 1. Repartición de las formas de posterioridad en el español peninsular (1930-2015)

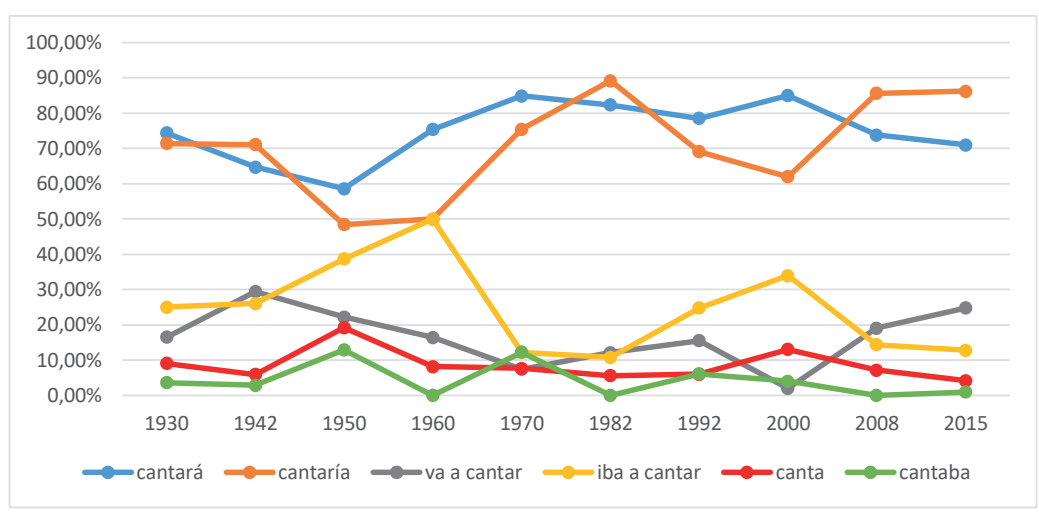

Como se muestra en el gráfico 1, en España tanto el futuro como el pospretérito no dejan de prevalecer sobre la perífrasis a lo largo de todo el período analizado, alcanzando casi siempre una frecuencia relativa superior al 50\%. Dicho de otro modo, los tiempos sintéticos con vector de posterioridad mantienen una posición estable en el sistema temporal del castellano y no parece que caigan paulatinamente en desuso. 
En cuanto a la perífrasis con verbo en presente, resaltemos que esta marca su presencia ya en los años treinta del siglo XX (16,5\%), pero no se ve que su empleo crezca decididamente con el paso del tiempo, superando solo tres veces el nivel de $20 \%$. Iba a cantar, por su parte, parece entrar en tres ocasiones en competencia con cantaría con una frecuencia relativa que supera al 30\%, lo cual no supone que se convierta de este modo en un fuerte candidato en la expresión de futuridad.

Los datos recogidos en el gráfico 1 confirman nuestras expectativas con respecto a canta y cantaba, que desempeñan un papel mucho menos significativo en la expresión de posterioridad, siendo formas típicas de la lengua hablada con una frecuencia casi siempre inferior al $10 \%$. A pesar de ello, podemos afirmar que se nota mucho más la competencia entre el presente pro futuro y la perífrasis que entre los futuros analítico y sintético, lo que se debe al uso elevado de este último. El copretérito, en cambio, cuyo uso es considerablemente menos reducido que el del presente, no se utiliza en casi la mitad de las novelas estudiadas y, por ello, sería arriesgado decir que compite con iba $a+$ infinitivo. Además, hay que resaltar que en nuestro corpus, tanto el presente como el copretérito no suelen venir acompañados de un marcador temporal para denotar futuridad, de lo que se deduce que es normalmente el contexto el que determina el tipo de referencia con la que se emplean dichos tiempos.

Como se desprende del gráfico 2, en el uso de cantará prevalece evidentemente el valor temporal y no parece que esa tendencia cambie pronto en el futuro, especialmente si nos fijamos en los datos recopilados en los años 2008 y 2015. Por lo que respecta a cantaría, la repartición de sus valores ya no es tan transparente y aunque predomina globalmente el empleo modal de dicha forma, no es verdad que el pospretérito deje de utilizarse para expresar lo venidero.

Teniendo en cuenta los resultados de los estudios acerca de la posterioridad en el español peninsular, no nos extraña la repartición general de las formas en cuestión, es decir, el predominio de cantará y cantaría sobre ir a + infinitivo y el uso relativamente reducido de canta y cantaba. 
Gráfico 2. Valor temporal vs. valor modal del futuro y del pos-pretérito en el español peninsular (1930-2015)

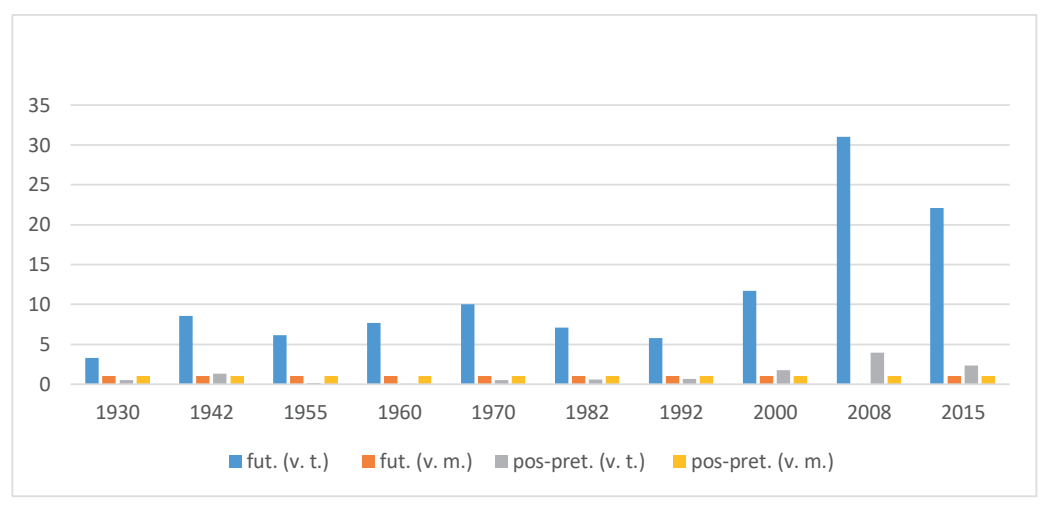

En lo que concierne a las llamadas formas periféricas (acompañantes), hemos de subrayar que su escasa presencia en la Península queda restringida exclusivamente al modo subjuntivo, es decir, a las formas vaya a cantar, fuera a cantar y fuese a cantar. Sin embargo, el número de ejemplos encontrados impide observar algún desarrollo de la perífrasis en el modo subjuntivo. Las demás formas periféricas no se han registrado en nuestro corpus, lo que no nos parece muy sorprendente, porque se consideran típicas del español de América. 


\section{Español de México}

Gráfico 3. Repartición de las formas de posterioridad en el español de México (1929-2015)

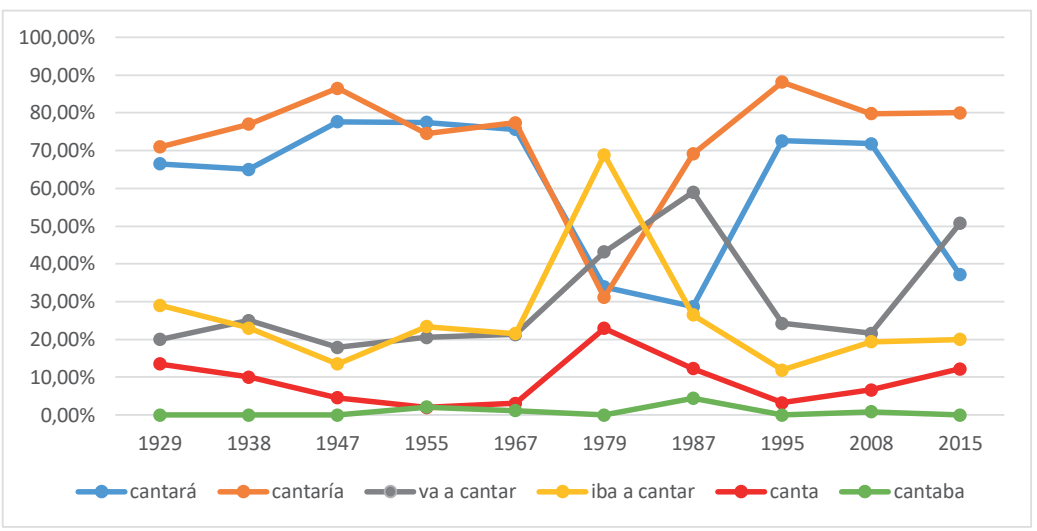

Por lo que se refiere al español de México (gráfico 3), es indudable que los futuros sintéticos, es decir, el futuro y el pospretérito, son los que se usan con mayor frecuencia a la hora de denotar posterioridad en las novelas mexicanas publicadas entre los años 1929 y 2015. Aun así, se ve que el reemplazo de las formas sintéticas por las analíticas queda reflejado en lo escrito, de modo que en Dos crímenes (1979), Señorita México (1987) y en Dos veces única (2015) hemos registrado el predominio de va a cantar sobre cantará. Amén de ello, en Dos crímenes (1979) salta a la vista que el empleo de iba a cantar es más común que el de cantaría.

En lo correspondiente al presente pro futuro, observemos que su presencia en la mayoría de los casos resulta marginal, siendo inferior al $10 \% \mathrm{y}$, por eso, en pocas ocasiones es posible registrar cierta competencia entre canta y va a cantar, lo cual, a nuestro modo de ver, habría que asociar más bien con el uso reducido de la perífrasis que con el creciente empleo de canta con referencia a lo venidero. La misma observación concierne al copretérito con valor de futuro, cuyo 
uso apenas se ha documentado en el análisis. Por último, conviene advertir que tanto el presente como el copretérito al denotar lo venidero no exigen en la mayoría de los casos la presencia de un marcador temporal, puesto que el significado de futuridad viene proporcionado por el contexto (la misma observación se refiere al español peninsular).

Gráfico 4. Valor temporal vs. valor modal del futuro y del pos-pretérito en el español de México (1929-2015)

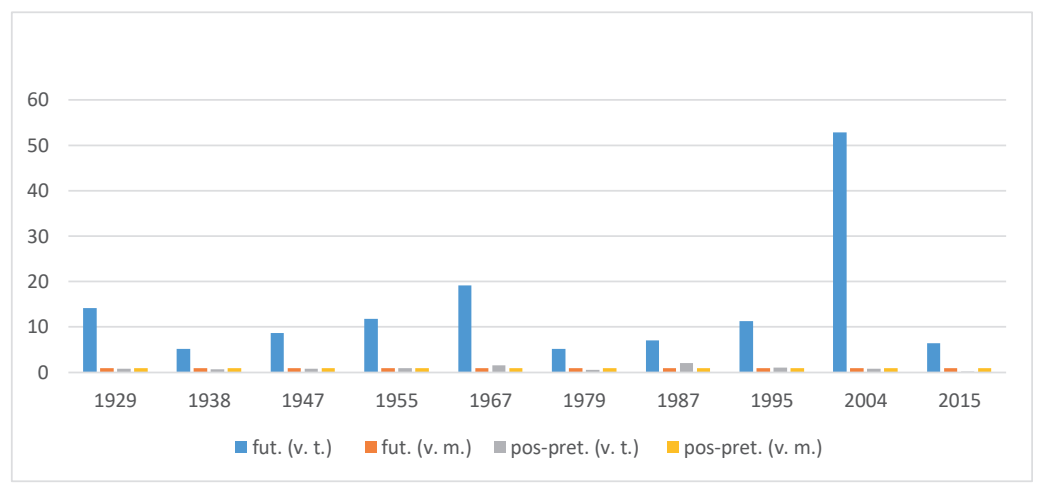

Según los datos recopilados en el gráfico 4, en el español mexicano la situación de cantará se parece mucho a la que se da en su variedad peninsular, de modo que en su uso vemos el predominio del valor temporal sobre el modal. Sin embargo, a diferencia de lo registrado en la Península, en México se observa con más claridad que la forma cantaría es utilizada sobre todo con valor metafórico. El hecho de que en el uso del llamado condicional predomine el valor modal se debe, hasta cierto punto, a la sustitución más frecuente del pospretérito por la perífrasis con verbo en copretérito a la hora de denotar posterioridad con respecto a un momento anterior al origen. 


\section{Español peninsular vs. español de México}

Gráfico 5. Uso de cantará, va a cantar y canta en el español peninsular y su variedad mexicana

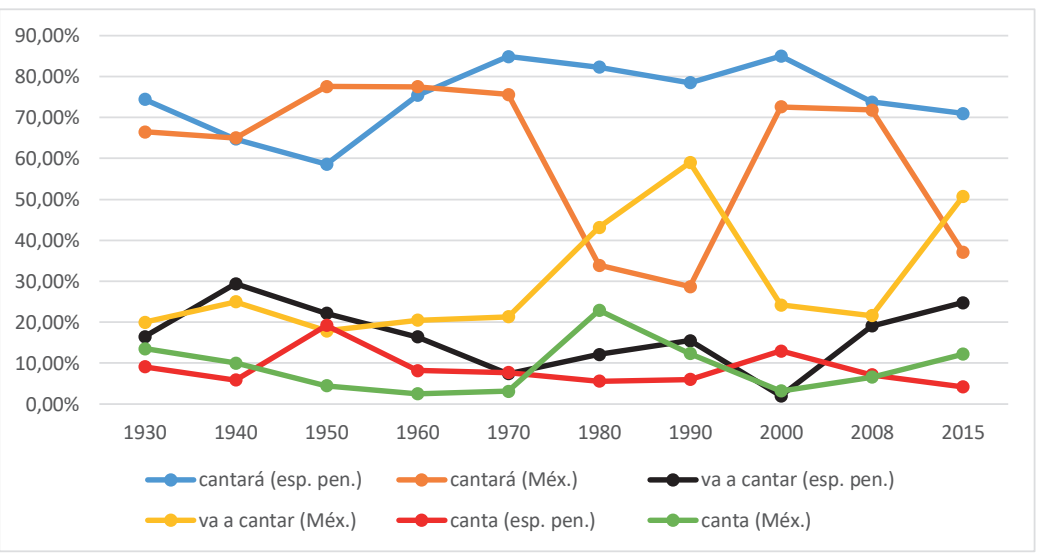

A la luz de lo presentado en el gráfico 5, está claro que el futuro en -rá mantiene una posición más estable en España que en México y, de manera paralela, la perífrasis con verbo en presente es usada más frecuentemente en el continente americano que en la Península. En cuanto al presente pro futuro, resulta imposible determinar en qué país su empleo es más extendido, pero queda fuera de toda duda que tenemos que ver con la forma utilizada esporádicamente en los dos. Además, destaca que en las novelas analizadas el presente así como el copretérito al denotar lo venidero raras veces exigen la presencia de un marcador temporal, dado que el significado de futuridad viene proporcionado por el contexto.

En el caso de las formas que expresan futuridad con respecto a un momento anterior al origen la comparación de su empleo en México y en España no permite observar una posición más fuerte por parte de cualquiera de ellas en uno de estos países. 
Gráfico 6. Uso de cantaría, iba a cantar y cantaba en el español peninsular y su variedad mexicana

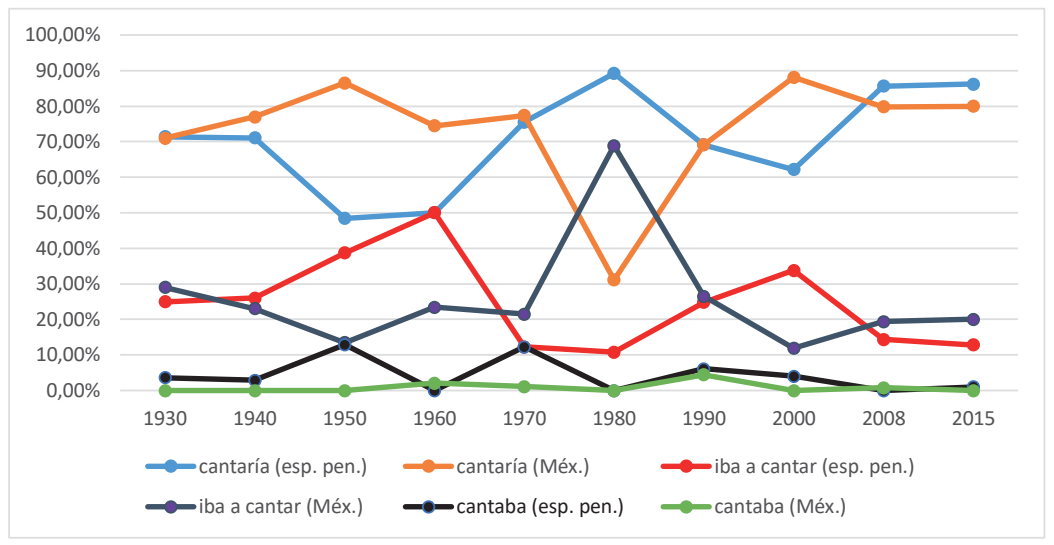

Según se advierte en el gráfico 6, el uso del copretérito con referencia a lo venidero parece algo más frecuente en el español peninsular, aunque en ambas variedades resulta marginal. Amén de ello, es evidente que ni cantará, ni cantaría pierden la estabilidad en el sistema temporal castellano, prevaleciendo en la expresión de lo posterior en la mayoría de las obras españolas y mexicanas recopiladas en el corpus.

Como era de esperar, en el español de México se han documentado más formas acompañantes que en el de España. A diferencia de lo observado en la Península, en México su uso no solo se restringe al modo subjuntivo, sino que también comprende irá a cantar e iría a cantar, empleadas solamente en la novela mexicana Al filo del agua del año 1947. Las únicas dos formas que no están registradas en el corpus son va a haber cantado e iba a haber cantado.

\section{Observaciones finales}

Tal y como ya hemos dicho, las obras literarias reflejan con cierto retraso los cambios sucedidos en la lengua y este es indudablemente el caso de nuestro corpus. Recordemos que tanto el uso de la perífrasis 
como el empleo del presente y del copretérito con referencia a lo venidero se consideran típicos de lo oral y, por ello, es comprensible que la lengua escrita muestre cierta resistencia a su uso.

Aun así, nuestro análisis demuestra que el proceso de sustitución que nos ocupa cuenta con mayor intensidad en México que en la Península, puesto que en tres obras mexicanas publicadas en los años 1979, 1987 y 2015 se ha documentado la superioridad de las formas analíticas sobre las sintéticas. De ahí se supone que el reemplazo de los futuros morfológicos por los perifrásticos se intensificó, al menos en la lengua literaria de México, en la segunda mitad del siglo $\mathrm{XX}^{1}$.

En lo que atañe a la repartición de los valores del futuro y del pospretérito, es evidente que cantará sigue empleándose sobre todo con valor temporal tanto en España como en México, mientras que en el caso de cantaría llama la atención un claro predominio del valor modal en ambos países. El hecho de que el pospretérito se utilice ante todo con dicho valor no nos parece particularmente extraño si tenemos en cuenta que ya en la época medieval los valores temporales y modales de cantaría $^{2}$ se repartían a la mitad (Company Company, 2006: 407-408).

De acuerdo con lo anteriormente expuesto, parece que ni el presente ni el copretérito usados con referencia a lo posterior se acercan a conseguir el estatus de las formas de futuridad. En realidad, en los dos países que nos ocupan el empleo de canta en muy pocas ocasiones supera el 15\% del total, compitiendo con la perífrasis exclusivamente en las obras en las que la presencia de esta última es reducida. En lo que corresponde al copretérito, su uso resulta aún más marginal que el del presente y, por tanto, prácticamente no hay rivalidad entre cantaba y las demás formas que denotan posterioridad con respecto a un momento anterior al origen.

1 Hay que destacar que el número de trabajos que tratan ese tema creció significativamente a partir de los años $60 \mathrm{y}$, por eso, parece posible que el proceso en cuestión cobrara aún mayor intensidad en aquella época.

2 Recuérdese que el pospretérito desde sus orígenes cuenta con dos valores modales: el de probabilidad y el de no-realidad, sometiéndose a dos tipos de dislocación temporal. 


\section{Bibliografía}

\section{Obras de consulta:}

AARON, J. E. (2007), "El futuro epistémico y la variación: gramaticalización y expresión de la futuridad desde 1600”, Moenia, 13, pp. 253-274.

BAUHR, G. (1989), El futuro en -ré e ir a + infinitivo en español peninsular moderno, Acta Universitatis Gothoburgensis, Göteborg.

BRAVO, A. (2008), La perifrasis «ir a +infinitivo» en el sistema temporal y aspectual del español, [on-line] https://www.researchgate.net/profile/ Ana_Bravo5/publication/39656884_La_perifrasis_ir_a_infinitivo_ en_el_sistema_temporal_y_aspectual_del_espanol/links/552bd5280c f29b22c9c1 feb6/La-perifrasis-ir-a-infinitivo-en-el-sistema-temporal-yaspectual-del-espanol, 25.06.2019.

COMPANY COMPANY, C. (2006), “Tiempos de formación romance II. Los futuros y condicionales”, en: Company Company, C. (coord.), Sintaxis histórica de la lengua española. Primera parte: La frase verbal, Fondo de Cultura Económica y Universidad Nacional Autónoma de México, México, pp. 349-422.

FLEISCHMAN, S. (1982), The Future in Thought and Language: Diachronic Evidence from Romance, Cambridge University Press, Cambridge, https:// doi.org/10.24201/nrfh.v32i2.2693.

HOPPER, P. J., TRAUGOTT, E. C. (2003), Grammaticalization, Cambridge University Press, Cambridge.

LACA, B. (2016), "Variación y semántica de los tiempos verbales: el caso del futuro”, [on-line] https://hal.archives-ouvertes.fr/hal-01372981/document, 7.08.2019.

SCHWEGLER, A. (1990), Analyticity and Syntheticity: A Diachronic Perspective with Special Reference to Romance Languages, Mouton de Gruyter, Berlin-New York.

\section{Fuentes del corpus:}

BARBA, A. (2008), Las manos pequeñas, Anagrama, S. A., Barcelona. CELA, C. J., (2011 [1950]), La colmena, Destino, S. A., Barcelona. CUAUHTÉMOC SÁNCHEZ, C. (2004), Los ojos de mi princesa, Ediciones Selectas Diamante, S. A. de C. V., Ciudad de México. 
FUENTES, C. (2001 [1967]), Cambio de piel, Bibliotex, S. L., Barcelona. GARCÍA HORTELANO, J. (2001 [1982]), Gramática parda, Bibliotex, S. L., Barcelona.

GUZMÁN, M. L. (1929), La sombra del caudillo, Porrúa, S. A., México, D. F. IBARGÜENGOITIA, J. (1988 [1979]), Dos crimenes, Grijalbo Mondadori, S. A., Barcelona.

MARÍAS, J. (2006 [1992]), Corazón tan blanco, Crítica, Barcelona.

MARSÉ, J. (1998 [1970]), La oscura historia de la prima Montse, Plaza\&Janés Editores, S. A., Barcelona.

MORO, J. (2015), A flor de piel, Planeta, S. A., Barcelona.

PÉREZ-REVERTE, A. (2003 [2000]), El oro del rey, Punto de Lectura, Madrid.

PONIATOWSKA, E. (2015), Dos veces única, Planeta Mexicana, S. A. de C. V., México, D. F.

ROMERO, J. R. (1964[1938]), La vida inútil de Pito Pérez, Casa de las Américas, La Habana.

RULFO, J. (1986 [1955]), Pedro Páramo, Cátedra, S. A., Madrid.

SALVADOR, T. (1960), El atentado, Planeta, S. A., Barcelona.

SENDERO, J. M. (1972 [1942]), Epitalamio del prieto Trinidad, Salvat Editores, S. A., Estella.

SERENA, E. (1993 [1987]), Señorita México, Plaza y Valdés Editores, México, D. F.

UNAMUNO, M. de. (1977 [1930]), San Manuel Bueno, mártir y tres historias más, Espasa-Calpe, S. A., Madrid.

YÁÑEZ, A. (1967 [1947), Al filo del agua, Casa de las Américas, La Habana. VOLPI, J. (2007 [1995]), La paz de los sepulcros, Planeta, S.A., Madrid. 